\title{
Landscape connectivity of the Grassland Biome in Mpumalanga, South Africa
}

\author{
Louise Fourie*, Mathieu Rouget\#, Mervyn Lötter ${ }^{+\$}$
}

\begin{abstract}
*Department of Plant Science, University of Pretoria, Pretoria, South Africa
${ }^{+}$Mpumalanga Tourism and Parks Agency, Lydenburg, South Africa

${ }^{\$}$ Restoration and Conservation Biology, School of Animal, Plant and Environmental Sciences, University of the Witwatersrand, Johannesburg, South Africa

\#Center for Invasion Biology, School of Agricultural, Environmental and Earth Sciences, University of KwaZulu-Natal, Pietermaritzburg, South Africa
\end{abstract}

Corresponding author: Mathieu Rouget, Land Use Planning and Management, School of Agricultural, Environmental and Earth Sciences, University of KwaZulu-Natal, Private Bag X01, Scottsville 3209, South Africa. Email: Rouget@ukza.ac.za Telephone no.: +27(0) 332605112.

Short running title: Connectivity of Mpumalanga's grasslands

\section{Abstract}

The South African Grassland biome is one of the most threatened biomes in South Africa. Approximately $45 \%$ of the Grassland biome area is transformed, degraded or severely invaded by alien plants and the remaining natural areas are highly fragmented. In this fragmented landscape, the connectivity between habitat patches is very important to maintain viable populations. In this study we aimed to quantify connectivity of the grassland biome in Mpumalanga using graph theory in order to identify conservation priorities and to direct conservation efforts. Graph theory-based connectivity indices have the ability to combine spatially explicit habitat data with species specific dispersal data and can quantify structural and functional connectivity over large landscapes. We used these indices to quantify the overall connectivity of the study area, to determine the influence of abandoned croplands on overall 
connectivity, and to identify the habitat patches and vegetation types most in need of maintaining overall connectivity. Natural areas were identified using 2008 land cover data for Mpumalanga. Connectivity within the Grassland Biome of Mpumalanga was analysed for grassland species with dispersal distances ranging from 50 to $1000 \mathrm{~m}$. The grassland habitat patches were mostly well connected, with $99.6 \%$ of the total habitat area connected in a single component at a threshold distance of $1000 \mathrm{~m}$. The inclusion of abandoned croplands resulted in a $33 \%$ increase in connectivity at a threshold distance of $500 \mathrm{~m}$. The habitat patches most important for maintaining overall connectivity were the large patches of continuous habitat in the upper and lower centres of the study area and the most important vegetation types were the Wakkerstroom Montane Grassland and the Eastern Temperate Freshwater Wetlands. These results can be used to inform management decisions and reserve design to improve and maintain connectivity in this biome.

Key words: secondary grassland, habitat fragmentation, conservation planning, abandoned croplands, threatened ecosystems

\section{Introduction}

Habitat loss and fragmentation are seen as the two biggest causes of biodiversity loss worldwide (Dirzo and Raven 2003; Wilcox and Murphy 1985), and it is still difficult to separate the effects of habitat fragmentation from the effects of habitat loss (Fahrig 2003). The effect of habitat fragmentation on biodiversity is also difficult to assess because of a time lag in species responses to changes in habitat configuration. This means that especially plant species diversity can decrease in fragmented landscapes for a further 50 to 100 years, even if the current landscape configuration is maintained (Lindborg and Eriksson 2004). Habitat fragmentation intensifies the effects of habitat loss and can be described as the increased isolation of habitat patches (Fahrig 2003). 
Habitat connectivity is increasingly used to quantify the isolation of habitat patches through fragmentation (Schumaker 1996), and can therefore be seen as a measure of the effect of fragmentation on the landscape. There is a wide range of definitions and measurements of fragmentation, and which definition and quantification used influences our understanding of the effect of fragmentation on biodiversity (Fahrig 2003). Connectivity refers to the degree of movement of organisms or processes, and is responsible for maintaining viable populations in fragmented landscapes (Crooks and Sanjayan 2006). Connectivity also facilitates juvenile dispersal, recolonization of unoccupied habitat patches and seasonal migration (Hanski 1998), and enables range shifts in response to climate change (Minor and Urban 2008). Quantifying connectivity is therefore essential to inform conservation plans and management decisions (Calabrese and Fagan 2004). However, connectivity measures have not been widely used for conservation planning in South Africa.

The temperate Grassland biome has the highest conservation risk of the world's biomes due to the very high rate of habitat loss and low protection (Hoekstra et al. 2005). This biome includes the grasslands of Europe and Asia, the American prairies, the temperate grasslands of Argentina, Uruguay, Australia and New Zealand as well as the South African Grassland biome (Henwood 1998). Historically the most diverse and productive of the world's 15 biomes, its fertile soils and moderate climate has made it one of the best environments for human settlement and agriculture (Henwood 1998).

The South African Grassland biome does not differ significantly from the global trend. High in species diversity, with 3378 plant species occurring in the core region (Bredenkamp et al. 2006), the South African Grassland biome is threatened by mining, urban development, agriculture, overgrazing, plantation forestry and climate change (Neke and Du Plessis 2004). The conservation of the biome is further complicated by the fact that many areas considered as natural are in fact abandoned croplands (Neke and Du Plessis 2004). These abandoned croplands are considered to have a lower species richness and especially grassland forb species have not been seen to return even 40 years after abandonment (Roux 1966). In South Africa's Mpumalanga 
province, that occupies $76495 \mathrm{~km}^{2}$ in the North East of South Africa, the biome has been substantially reduced as $44 \%$ has been transformed, mainly through agriculture, plantations and mining (Ferrar and Lötter 2007). The grassland biome is also highly fragmented, with only $4 \%$ of the remaining natural areas bigger than $100 \mathrm{~km}^{2}$ (Neke and Du Plessis 2004).

As the world's ecosystems are increasingly being transformed through human activities it is important to monitor and track the conservation status of ecosystems and identify those most in need of conservation attention (Rodríguez et al. 2011). Accordingly, the IUCN developed criteria for identifying such threatened ecosystems, based mostly on the rate of decline and the size of the current distribution of ecosystems (Rodríguez et al. 2011). Criteria for the listing of threatened ecosystems have also been developed for South Africa by the South African National Biodiversity Institute and the Department of Environmental Affairs and Tourism (SANBI and DEAT 2009). Even though the habitat fragmentation of an ecosystem is listed as a criterion to identify threatened ecosystems in South Africa, it has not yet been used, as further testing is still needed to determine the workability of this criterion (SANBI and DEAT 2009). Connectivity measures may provide a way to quantify the potential effects of fragmentation of different vegetation types or ecosystems, and may help with the identification of threatened ecosystems.

Even though an analysis of connectivity of the grassland biome in Mpumalanga is highly necessary to determine and manage the effects of increased habitat fragmentation in this biome, computational limitations previously prevented the quantification of connectivity in this large area. With the recent development of habitat connectivity metrics based on graph theory, it became possible to obtain a detailed quantification of large landscapes such as the grassland biome in Mpumalanga.

The overall aim of this study is therefore to investigate and quantify connectivity of grassland habitat patches in Mpumalanga using graph theory. This is done by (1) investigating overall connectivity in Mpumalanga in terms of two indices: the Number 
of Components and the Integral Index of Connectivity; (2) investigating the importance of abandoned croplands for maintaining connectivity in the landscape and (3) identifying the habitat patches and vegetation types most important for maintaining overall connectivity.

\section{Methods}

\section{Study area}

The area studied in this project was the part of the South African Grassland biome that falls in the Mpumalanga province of South Africa. The grassland biome occupies $61 \%$ of Mpumalanga with a total area of $47810 \mathrm{~km}^{2}$ of which $44 \%$ is transformed by the removal or radical disturbance of natural vegetation (Ferrar and Lötter 2007). Mpumalanga's grasslands occur mainly on fertile soils and the biggest threats to the conservation of the grassland biome are agriculture, plantation forestry, alien plant invasion and open cast mining for coal (Ferrar and Lötter 2007). The biome can be divided into the high-altitude mountain grasslands that are dominated by C3 species and are rich in endemics, and the lower-altitude highveld grasslands that have fewer endemics and are dominated by C4 species (Mucina et al. 2006). The eastern high-rainfall region of the biome is simultaneously the region with the highest diversity of animals and plants, and the area with the highest risk of transformation (Neke and Du Plessis 2004). The grassland biome in Mpumalanga contains a high number of rare and threatened species (Ferrar and Lötter 2007).

\section{Mapping of abandoned croplands}

The high occurrence of abandoned croplands in the grassland biome is of conservation concern, as they are not usually captured by land cover datasets derived from satellite information and are therefore usually classified as natural in these land cover datasets. These abandoned croplands have a much lower species diversity than pristine grassland (Roux 1966), but they may play an important role in connecting pristine grassland habitat patches in the landscape. 
The locations of abandoned croplands were determined by digitising the areas mapped as cultivated on the first edition 1:50 000 topographical maps. These first edition topographical maps were obtained from the Chief Directorate: National Geospatial Information of the Department of Rural Development \& Land Reform of the Republic of South Africa. These maps were generally compiled from aerial photographs, and indicate the locations of among other things cultivated lands, orchards and vineyards, trees and bush at the time the maps were drawn. The dates on the first edition of these maps range between 1939 and 1986 with a median of 1962. The locations of areas cultivated on the first edition topographical maps were then compared to the 1984 and 2008 land cover datasets of Mpumalanga to identify previously cultivated areas, which are now classified as natural and therefore represent abandoned croplands. The 1984 and 2008 land cover datasets used were produced for the Mpumalanga Parks Board by GeoTerralmage (Pty) Ltd. These land cover datasets distinguish between mined areas, cultivated areas, urban areas, afforested areas and untransformed 'natural' areas and were mapped from Landsat 5 satellite images. Accuracy of both the topographical maps and the land cover datasets were spot-checked against recent satellite images, and were accurate to a fine scale. The different maps lined up well when overlaid. Small off-cut pieces caused by small spatial differences between the two datasets were minimal, and were eliminated when habitat patches smaller than 5 ha were removed (see next section).

\section{Defining grassland habitat patches}

In order to quantify the connectivity between habitat patches of natural grassland in Mpumalanga, the location and the extent of these habitat patches had to be determined from the 2008 land cover for Mpumalanga as well as the abandoned cropland dataset. A habitat patch was considered as any area not transformed by cultivation, plantation forestry, urban development or mining in 2008 , and a distinction was made between pristine grassland patches and abandoned croplands. The major road network was used to divide the remaining habitat into smaller patches. All habitat patches smaller than 5 ha were removed as computational limitations of the 
ConeforSensinode (Saura and Torné 2009) software restricted the number of habitat patches that could be processed. These removed patches were mostly small off-cut areas caused by the overlay of the different datasets, and were an insignificant proportion of the total grassland habitat area. The resulting habitat patch layer contained 3681 grassland habitat patches with a total area of $30076 \mathrm{~km}^{2}$, of which $3056 \mathrm{~km}^{2}$ was abandoned croplands.

\section{Quantifying connectivity}

Connectivity can be described from different perspectives and scales (Crooks and Sanjayan 2006). Landscape connectivity can be seen as a result of both the specific species attributes (dispersal distance) and the spatial arrangement of habitat patches in the landscape (Tischendorf and Fahrig 2000). The arrangement of habitat patches in the landscape determines the structural connectivity. Functional connectivity describes the behavioural response of a specific organism to the landscape structure and is determined using attributes of the specific species, such as dispersal distance (Tischendorf and Fahrig 2000). Although structural connectivity is relatively easy to measure, functional connectivity is a feature of the specific organisms studied and the same landscape can have different levels of connectivity for different organisms (Tischendorf and Fahrig 2000).

There are more than 60 connectivity metrics (Rayfield et al. 2011) with various data requirements, information yield and performance depending on the specific ecological situation (Calabrese and Fagan 2004). Some of the most widely used connectivity metrics include the nearest neighbour distance, spatial pattern indices, graph theoretic indices, buffer radius and observed emigration and immigration (Calabrese and Fagan 2004).

We suggest that graph theoretic connectivity metrics provide an appropriate balance between initial data requirements and the detail of the results, and are also more computationally efficient than most connectivity metrics (Calabrese and Fagan 2004). Graphs are representations of more complex real systems (Urban et al. 2009) and represent habitat as a set of habitat patches (nodes) and connections between 
habitat patches (links or edges) (Calabrese and Fagan 2004). Graph theory can describe structural or functional connectivity, depending on the way the habitat patches and links are represented (Rayfield et al. 2011). Structural connectivity will be represented when the links contain information about the structure and arrangement of habitat patches, and functional connectivity will be represented when additional information such as dispersal distance is used. Nodes and links can be assigned weights representing patch size or quality, or the distance or effective distance of links (Rayfield et al. 2011). Graph theory connectivity metrics can be used over broad spatial scales with many habitat patches, and are flexible in the incorporation of additional information(Calabrese and Fagan 2004; Rayfield et al. 2011).

In this study graph theoretic indices were used to quantify a) the overall connectivity of grassland habitat patches in Mpumalanga, b) the importance of individual grassland habitat patches for overall connectivity, and c) connectivity in different grassland vegetation types. The area of habitat patches as well as edge-toedge Euclidian distances between habitat patches were calculated using ArcGIS 9 and the Conefor inputs GIS extension (www.jennessent.com/arcgis/conefor_inputs; accessed 03-10-2011). The program ConeforSensinode 2.2 was used to calculate the connectivity indices. This program uses graph structures to calculate indices and also has the ability to determine individual patch importance for overall landscape connectivity (Saura and Pascual-Hortal 2007a; Saura and Torné 2009).

\section{Quantifying overall landscape connectivity with and without abandoned croplands}

The Number of Components and the Integral Index of Connectivity (PascualHortal and Saura 2006; Saura and Pascual-Hortal 2007a; Saura and Pascual-Hortal 2007b) were used to determine to what extent the presence of abandoned croplands improve the overall landscape connectivity. Two separate analyses were done: first using only pristine natural habitat patches excluding abandoned croplands, and then using habitat patches consisting of both abandoned croplands and pristine grassland. The Integral Index of Connectivity was chosen above the similar probabilistic Probability of Connectivity (PC) index which, instead of the binary connection or no 
connection model of connectivity used by the Integral Index of Connectivity, can take into account various probabilities of direct dispersal between two habitat patches (Bodin and Saura 2010). The Integral Index of Connectivity was preferred for this study, as the absence of reliable species specific dispersal information makes it impossible to motivate decisions made on the probabilities used to calculate the Probability of Connectivity. The Integral Index of Connectivity does not demonstrate the same problems associated with many other connectivity indices, where there is an increase in connectivity with increased fragmentation (Tischendorf and Fahrig 2000), or no connectivity predicted for a landscape occupied by one big habitat patch (Tischendorf and Fahrig 2000), or a lack of response of the index to the loss of big isolated habitat patches (Pascual-Hortal and Saura 2006).

A component is a set of habitat patches with a connection between every two habitat patches in the component. As connectivity across the landscape increases, the number of components will usually decrease (Saura and Pascual-Hortal 2007a). More connected landscapes will also tend to consist of one big component in which all the habitat patches are connected. Under specific circumstances, the percentage of total habitat area that is in the biggest component will also increase as the landscape gets more connected.

The Integral Index of Connectivity is recommended as the best binary index for landscape connectivity measurements (Pascual-Hortal and Saura 2006; Saura and Pascual-Hortal 2007b). The advantage of the Integral Index of Connectivity is that it incorporates habitat amount (or patch quality) and connectivity into one concept. This means that the habitat patch itself is considered as an area where connectivity occurs (Pascual-Hortal and Saura 2006). The Integral Index of Connectivity (IIC) ranges from 0 to 1 , increasing with improved connectivity (Pascual-Hortal and Saura 2006) and is calculated by the formula

$I I C=\frac{\sum_{i=1}^{n} \sum_{j=1}^{n} \frac{a_{i} \cdot a_{j}}{1+n l_{i j}}}{A_{L}^{2}}$ 
where $n$ is the total number of nodes, $a_{i}$ and $a_{j}$ are the attributes (any quantitative characteristic of the node that may be relevant; in this study patch area has been used as an attribute) of nodes $i$ and $j, n l_{i j}$ is the number of links in the shortest path between patches $i$ and $j$, and $A_{L}$ is the maximum landscape attribute (the total landscape area, consisting of both habitat and non-habitat areas) (Saura and Pascual-Hortal 2007a; Saura and Pascual-Hortal 2007b).

Landscape connectivity is species-specific, and the same landscape has various levels of connectivity for different species, depending on the specific species dispersal abilities (Crooks and Sanjayan 2006). To incorporate the responses of different species to the landscape pattern the analysis was repeated with a range of different threshold distances; $50 \mathrm{~m}, 100 \mathrm{~m}, 250 \mathrm{~m}, 500 \mathrm{~m}$ and $1000 \mathrm{~m}$. These threshold distances were used because there is no consistent and reliable information available on the dispersal distances of grassland species. Because of the lack of this information, a range of different threshold distances were used to get an idea of the landscape connectivity over a range of different dispersal distances. The threshold distance specifies at which inter-patch distance two patches would be considered as connected or not connected. For example; if the threshold distance for a connectivity analysis is $500 \mathrm{~m}$, every two patches that are less than $500 \mathrm{~m}$ apart will be considered as connected.

\section{Quantifying the importance of individual patches for overall connectivity}

In order to conserve connectivity in increasingly fragmented landscapes the conservation of individual habitat patches can be prioritised according to their contribution to overall landscape connectivity (Baranyi et al. 2011). Different connectivity indices can be used to identify these key elements in the landscape. The connectivity values for individual patches were calculated by removing each patch in turn and measuring the difference in the Integral Index of Connectivity for the landscape. The difference in the Integral Index of Connectivity was calculated for each patch as:

$\operatorname{dIIC}(\%)=100 \cdot \frac{I I C-I I C_{\text {remove }}}{I I C}$ 
Where $I / C$ is the overall index value when all nodes are present in the landscape and $\| C_{\text {remove }}$ is the overall index value after the removal of the specific habitat patch (Pascual-Hortal and Saura 2006; Saura and Pascual-Hortal 2007a). The values for individual patches were calculated at a distance threshold of $50 \mathrm{~m}$. Because this study investigates landscape-scale connectivity over a large area for a biome, it is impossible to consider every species unique dispersal distance and habitat requirements and therefore a distance threshold of $50 \mathrm{~m}$ was used to calculate the values of individual patches. The seed dispersal abilities of plants with long distance dispersal methods are extremely difficult to determine (Cain et al. 2000), and are further complicated by the multiple dispersal vectors responsible for seed dispersal of almost any given plant species (Nathan 2007). The dispersal distances of some long distance and short distance wind dispersed grassland forb species has been estimated at less than $100 \mathrm{~m}$ and less than $10 \mathrm{~m}$ respectively (Soons et al. 2004). The distance threshold of $50 \mathrm{~m}$ can therefore be considered as an intermediate dispersal distance for wind dispersed grassland forb species.

\section{Quantifying connectivity of vegetation types}

The map of vegetation types used in the Mpumalanga Biodiversity Conservation Plan (Ferrar \& Lötter 2007) was used in this study. This map was refined from the Vegetation Map for South Africa, Lesotho and Swaziland produced by the South African National Biodiversity Institute (SANBI) in 2005 (Mucina et al. 2005). The Vegetation Map of South Africa, Lesotho and Swaziland is currently the latest and most used vegetation map available in the country. This vegetation map consists of 441 different vegetation types, and was created using topography, geology, soils, land types, climate and plant distribution data from different databases (Mucina et al. 2006).

In this study the connectivities of vegetation types were quantified in two ways. The weighted importance of each vegetation type for overall connectivity was calculated as: 
Weighted Importance of vegetation type

$$
=\frac{\sum_{i=1}^{n}\left(d I I C_{i} \cdot \text { Area }_{\mathrm{i}}\right)}{\text { Total area of vegetation type in Mpumalanga }}
$$

where $n$ is the total number of nodes (habitat patches) in the vegetation type, $d I I C_{i}$ is the percentage difference in the Integral Index of Connectivity for the entire landscape when node $i$ is removed and Area $_{i}$ is the area of node $i$ in the vegetation type. Connectivity for each vegetation type was also quantified by the percentage of the patch area of the vegetation type that is a part of the largest component in the whole landscape (main landscape component). It is expected that as a vegetation type becomes less connected, a smaller percentage of the total patch area will be in the main landscape component.

\section{Results}

\section{Quantifying overall landscape connectivity and the importance of individual patches}

The grassland habitat patches (including both abandoned croplands and pristine grassland) in Mpumalanga were mostly well-connected, with 47 different components and $99.6 \%$ of the total habitat patch area in the main component at a threshold distance of $1000 \mathrm{~m}$ (Table 1). Although this means that there were still 47 clusters of habitat patches that had no connections between them, most habitat patches were connected in one big component that spanned the entire landscape and occupied a large portion of the total habitat patch area. The Number of Components increased rapidly as the threshold distance decreased (Figure 1a), but the largest part of the landscape remained connected in one component, with $94 \%$ of the total habitat patch area in the main component at a threshold distance of $50 \mathrm{~m}$ (Table 1). Both the Number of Components as well as the Integral Index of Connectivity showed an increase in connectivity as the threshold distance was increased (Figure 1). This was expected, because as the threshold distance was increased, more patches became connected to each other. Three areas became noticeably disconnected as the threshold distance decreased (Figure 2). These areas were in the extreme north-east and south-east of the study area. 
The inclusion of abandoned croplands as habitat patches resulted in an improvement in connectivity according to both the Number of Components and the Integral Index of Connectivity (Figure 1a \& b). Abandoned croplands resulted in a $33 \%$ increase in the Integral Index of Connectivity at a threshold distance of $500 \mathrm{~m}$ (Figure 1b). Although the inclusion of all abandoned croplands resulted in an improvement in connectivity, no single abandoned cropland patch led to a major improvement in overall connectivity on its own. The largest improvement in IIC as a result of the inclusion of a single abandoned cropland habitat patch was $0.2 \%$.

The most important habitat patches supporting landscape connectivity, as calculated by the difference in the overall Integral Index of Connectivity caused by the removal of the patch, were the large patches of continuous habitat in the upper centre and the lower centre of the study area (Figure 3). The largest difference in the overall Integral Index of Connectivity caused by the removal of a single patch was $10.6 \%$, while the removal of several small patches made no difference.

\section{Quantifying connectivity of vegetation types}

A distinction was made between the most important vegetation types supporting overall connectivity and the most connected vegetation types. The most important vegetation types for maintaining overall connectivity, as measured by the weighted average of the importance of the patches in the vegetation type, were the Wakkerstroom Montane Grassland, Eastern Temperate Freshwater Wetlands, Steenkampsberg Montane Grassland and Lydenburg Thornveld (Table 2, Figure 4). This may be explained by the relatively large habitat patches and central locations of these vegetation types. The least important vegetation types for maintaining overall connectivity were the Northern Escarpment Quartzite Sourveld, the Northern Escarpment Dolomite Grassland and the Barberton Montane Grassland (Table 2, Figure 4). These vegetation types are mostly located on the borders of the study area and are severely impacted by habitat loss and fragmentation.

Most vegetation types were well connected as indicated by the percentage of the total patch area of the vegetation type that was within the largest component 
(Table 2). The most connected vegetation types were the Wakkerstroom Montane Grassland, Low Escarpment Moist Grassland and Lydenburg Thornveld (Table 2). Most of the habitat patches of these vegetation types were connected in one component to at a threshold distance of $50 \mathrm{~m}$. The least connected vegetation types were the Barberton Montane Grassland, Northern Escarpment Quartzite Sourveld and the Northern Escarpment Dolomite Grassland (Table 2). These were the only three vegetation types with less than $90 \%$ patch area connected to the largest patch in the landscape at a threshold distance of $50 \mathrm{~m}$. The Barberton Montane Grassland was the most fragmented vegetation type, with less than $40 \%$ of the total patch area in the vegetation type connected to the main landscape component at a threshold distance of $50 \mathrm{~m}$, and deserves further conservation attention. Only $6.3 \%$ of habitat patch area in the Barberton Montane Grassland vegetation type was connected to the study area's main landscape component. This vegetation type was poorly connected to other grassland vegetation types, but its habitat patches were well connected to each other, with $79 \%$ of habitat patch area connected in one component.

\section{Discussion}

This study found the grassland biome of Mpumalanga to be relatively well connected despite a high degree of habitat loss. Indeed, $93.6 \%$ of the total grassland habitat patch area ( $27.6 \%$ of the number of patches) is connected in a single component at a threshold distance of $50 \mathrm{~m}$ (Table 1). However, the percentage of the total grassland habitat patch area connected to the largest component may not give a true representation of actual connectivity. Even though two patches are in the same component, movement between these patches may require an organism to use several small patches as stepping stones, and cross the matrix multiple times. The grassland habitat patches of Mpumalanga are well connected compared to European grasslands (Soons et al. 2005).

Maintaining connectivity of the grassland habitat patches in Mpumalanga plays an important role in the persistence of organisms and processes when habitat loss and fragmentation increase, and enables range shifts of organisms as an adaptation to 
climate change (Crooks and Sanjayan 2006). This study identified the habitat patches and vegetation types that are the most critical for the persistence of overall habitat connectivity and can serve as a guideline to direct conservation efforts. The identification of habitat patches and vegetation types supporting overall connectivity should help with the prioritisation of conservation efforts. This process is currently underway in the update of the province conservation plan (see Ferrar \& Lötter, 2007 for the first version). Information about the landscape connectivity of the grassland biome in Mpumalanga can also be used to identify important areas for rehabilitation, and to identify areas most important to include in a protected areas network.

The three least important vegetation types for maintaining overall connectivity according to the weighted difference in Integral Index of Connectivity were also the least connected vegetation types with the smallest percentage of total patch area in the main patch. These three vegetation types (Northern Escarpment Quartzite Sourveld, Northern Escarpment Dolomite Grassland and Barberton Montane Grassland) are on the eastern edge of the grassland biome distribution in Mpumalanga, are adjacent to and interspersed with savanna vegetation, and are also heavily transformed through plantation forestry (Figure 3). At a threshold distance of $50 \mathrm{~m}$, the Frankfort Highveld Grassland vegetation type is the fourth least important vegetation type for overall connectivity, but is $99.7 \%$ connected to the main component in the landscape. This highlights the difference between the importance of a vegetation type contributing towards overall connectivity, and how well a vegetation type is connected. Areas on the border of the study area have a lower importance for overall connectivity than central areas even though they may be well connected to the rest of the landscape. However, the lower importance of areas on the border of the study area may be a cause of an artificial effect of the border on the results, and an analysis including areas immediately across the border may show different results. The most important habitat patches for supporting overall connectivity are in or near ecosystems listed as endangered (the Blyde Quartzite Grassland, Chrissiesmeer Panveld and Dullstroom Plateau Grasslands) (National Environmental Management 
Act, 2011). The results confirm the endangered status of these ecosystems and can be an important tool to motivate and direct conservation efforts.

Although this study quantified overall landscape connectivity, functional connectivity is specific to each organism, and the same landscape may be found to be connected for one species and unconnected for another (Bunn et al. 2000). In this study the matrix was treated as homogenous, but in practice some land cover types may be more favourable for dispersal. Additionally, different habitat patches may have different values to different organisms, and if available, species specific information may inform a habitat quality attribute to be considered in the analysis. Even though this landscape is well connected at the $50 \mathrm{~m}$ distance threshold, this is not necessarily true for all the organisms occurring in this landscape. Given the absence of species specific dispersal data this study used a general dispersal distance that can be applied to many species. A separate analysis should incorporate specific species of interest, such as threatened species, but there is very little information available on the dispersal distances of South African grassland species, and further studies in this area would be valuable. The exclusion of species specific data and the broad definition of habitat patches used in this study may be reason for it to be seen as oversimplified. However, for a single analysis of a large landscape with many diverse organisms, it is impossible to account for all dispersal distances and habitat preferences for each species.

The use of the amount of fragmentation has been suggested as a criterion for identifying threatened terrestrial ecosystems in South Africa but has not been used yet because of insufficient testing (SANBI and DEAT 2009). The loss in habitat connectivity caused by fragmentation can be relatively easy to measure. Mpumalanga currently has one ecosystem classified as critically endangered, 11 ecosystems as endangered and 20 as vulnerable (SANBI and DEAT 2009). The Northern Escarpment Quartzite Sourveld vegetation type is not considered as endangered, but it is the most fragmented grassland vegetation type in Mpumalanga (Table 2). The second and third most fragmented and least connected vegetation types, the Northern Escarpment Dolomite 
Grassland and the Barberton Montane Grassland, are classified as vulnerable (SANBI and DEAT 2009). These vegetation types or ecosystems may be more threatened than currently realised due to habitat fragmentation and loss of connectivity.

The use of general connectivity analyses plays an important role in conservation planning as it identifies areas of the landscape that are connected, it identifies the critical threshold at which the landscape is connected, and it identifies the important connections between patches (Galpern et al. 2011). Priority areas for conservation are usually chosen by their ability to contribute to the viability of several species (Visconti and Elkin 2009). This ability is influenced not only by the quality of the habitat, but also by its location with regards to other habitat patches (connectivity).

Although connectivity measures in conservation planning are mainly used to identify key connector patches (Bodin and Saura 2010; Saura et al. 2011b; Vergara et al. 2010), these measures have also been used to evaluate temporal changes in connectivity (Saura et al. 2011a) and to assess the effects of land use and land use change on connectivity (Theobald et al. 2011).

Until recently, the use of connectivity metrics to inform conservation decisions have mainly been species specific and focused on identifying important connecting habitat patches for specific species. The use of graph theory connectivity indices have great potential in accounting for the loss of specific habitat patches on habitat connectivity for a species or an ecosystem, as well as predicting the success of a protected area network in the conservation of threatened species (Neel 2008). These connectivity characteristics of a landscape can be evaluated even without speciesspecific dispersal data, by using a range of different threshold distances (Neel 2008).

This study used graph theoretic metrics to quantify landscape connectivity in a way that is not specific to certain species. Instead, we gave a broad quantification of landscape connectivity over a range of different dispersal distances. This more inclusive method proved a way to include connectivity considerations in conservation planning in areas that lack species specific dispersal information. This study is unique in that it quantified the contribution of abandoned croplands (areas usually seen as 
degraded and not useful for conservation) to landscape connectivity. We found that the inclusion of abandoned croplands does indeed increase the connectivity of the landscape. The implication of this finding is that the importance of areas for conservation should not only be a function of the vegetation quality of the area, but of its location as well.

\section{Acknowledgements}

This research was made possible by funding from the University of Pretoria and the National Research Foundation of South Africa. Land cover datasets were supplied by the Mpumalanga Tourism and Parks Agency. MR acknowledges funding from the South African Research Chairs Initiative of the Department of Science and Technology and National Research Foundation of South Africa.

\section{References}

Baranyi G., Saura S., Podani J. \& Jordán F. (2011) Contribution of habitat patches to network connectivity: Redundancy and uniqueness of topological indices. Ecological Indicators 11, 1301-10.

Bodin Ö. \& Saura S. (2010) Ranking individual habitat patches as connectivity providers: Integrating network analysis and patch removal experiments. Ecological Modelling 221, 2393-405.

Bredenkamp G. J., Brown L. R. \& Pfab M. F. (2006) Conservation value of the Egoli Granite Grassland, an endemic grassland in Gauteng, South Africa. Koedoe 49, 59-66.

Bunn A. G., Urban D. L. \& Keitt T. H. (2000) Landscape connectivity: A conservation application of graph theory. Journal of Environmental Management 59, 265-78.

Cain M. L., Milligan B. G. \& Strand A. E. (2000) Long-distance seed dispersal in plant populations. American Journal of Botany 87, 1217-27. 
Calabrese J. M. \& Fagan W. F. (2004) A comparison-shopper's guide to connectivity metrics. Frontiers in Ecology and the Environment 2, 529-36.

Crooks K. R. \& Sanjayan M. (2006) Connectivity conservation: maintaining connections for nature. In: Connectivity Conservation (eds K. R. Crooks and M. Sanjayan). Cambridge University Press, Cambridge.

Dirzo R. \& Raven P. H. (2003) Global state of biodiversity and loss. Annual Review of Environment and Resources 28, 137-67.

Fahrig L. (2003) Effects of Habitat Fragmentation on Biodiversity. Annual Review of Ecology, Evolution, and Systematics 34, 487-515.

Ferrar A. A. \& Lötter M. C. (2007) Mpumalanga Biodiversity Conservation Plan Handbook. Mpumalanga Tourism \& Parks Agency, Nelspruit.

Galpern P., Manseau M. \& Fall A. (2011) Patch-based graphs of landscape connectivity: A guide to construction, analysis and application for conservation. Biological Conservation 144, 44-55.

Hanski I. (1998) Connecting the parameters of local extinction and metapopulation dynamics. Oikos 83, 390-6.

Henwood W. D. (1998) An overview of protected areas in the temperate grassland biome. Parks 8, 3 - 8 .

Hoekstra J. M., Boucher T. M., Ricketts T. H. \& Roberts C. (2005) Confronting a biome crisis: Global disparities of habitat loss and protection. Ecology Letters 8, 23-9.

Lindborg L. \& Eriksson O. (2004) Historical Landscape Connectivity Affects Present Plant Species Diversity. Ecology 85, 1840-1845.

Minor E. S. \& Urban D. L. (2008) A graph-theory framework for evaluating landscape connectivity and conservation planning. Conservation Biology 22, 297-307. 
Mucina L., Hoare D. B., Lötter M. C., Du Preez P. J., Rutherford M. C., Scott-Shaw C. R., Bredenkamp G. J., Powrie L. W., Scott L., Camp K. G. T., Cilliers S. S., Bezuidenhout H., Mostert T. H., Siebert S. J., Winter P. J. D., Burrows J. E., Dobson L., Ward R. A., Stalmans M., Oliver E. G. H., Siebert F., Schmidt E., Kobisi K. \& Kose L. (2006) Grassland biome. In: The vegetation of South Africa, Lesotho and Swaziland (eds L. Mucina and M. C. Rutherford). South African National Biodiversity Institute, Pretoria.

Mucina L., Rutherford M.C. \& Powrie L. W. (2006) The logic of the map: Approaches and procedures. In: The vegetation of South Africa, Lesotho and Swaziland (eds L. Mucina and M. C. Rutherford). South African National Biodiversity Institute, Pretoria.

Mucina L., Rutherford M. C. \& Powrie L. (2005) Vegetation Map of South Africa, Lesotho and Swaziland. South African National Biodiversity Institute, Pretoria.

Nathan R. (2007) Total dispersal kernels and the evaluation of diversity and similarity in complex dispersal systems. In: Seed dispersal: theory and its application in a changing world (eds A. J. Dennis, E. W. Schupp, R. J. Green and D. A. Westcott) pp. 252 - 76. CABI, Oxfordshire.

Neel M. C. (2008) Patch connectivity and genetic diversity conservation in the federally endangered and narrowly endemic plant species Astragalus albens (Fabaceae). Biological Conservation 141, 938-55.

Neke K. S. \& Du Plessis M. A. (2004) The Threat of Transformation: Quantifying the Vulnerability of Grasslands in South Africa. Conservation Biology 18, 466-77.

Pascual-Hortal L. \& Saura S. (2006) Comparison and development of new graph-based landscape connectivity indices: towards the proirization of habitat patches and corridors for conservation. Landscape Ecology 21, 959-67.

Rayfield B., Fortin M.-J. \& Fall A. (2011) Connectivity for conservation: a framework to classify network measures. Ecology 92, 847-58. 
Rodríguez J. P., Rodríguez-Clark K. M., Baillie J. E. M., Ash N., Benson J., Boucher T., Brown C., Burgess N. D., Collen B., Jennings M., Keith D. A., Nicholson E., Revenga C., Reyers B., Rouget M., Smith T., Spalding M., Taber A., Walpole M., Zager I. \& Zamin T. (2011) Establishing IUCN red list criteria for threatened ecosystems. Conservation Biology 25, 21-9.

Roux E. (1966) Grass: a story of Frankenwald. Oxford, Cape Town.

SANBI \& DEAT. (2009) Threatened Ecosystems in South Africa: Descriptions and Maps. DRAFT for Comment. South African National Biodiversity Institute, Pretoria, South Africa.

Saura S., Estreguil C., Mouton C. \& Rodríguez-Freire M. (2011a) Network analysis to assess landscape connectivity trends: Application to European forests (1990-2000). Ecological Indicators 11, 407-16.

Saura S.\& Pascual-Hortal, L. (2007a) Conefor Sensinode 2.2 User's Manual: Software for quantifying the importance of hibitat patches for maintaining landscape connectivity through graphs and habitat availability indices. University of Lleida, Spain.

Saura S. \& Pascual-Hortal L. (2007b) A new habitat availability index to integrate connectivity in landscape conservation planning: comparison with existing indices and application to a case study. Landscape and Urban Planning 83 (2-3), 91-103.

Saura S. \& Torné J. (2009) Conefor Sensinode 2.2: A software package for quantifying the importance of habitat patches for landscape connectivity. Environmental Modelling \& Software 24, 135-9.

Saura S., Vogt P., Velázquez J., Hernando A. \& Tejera R. (2011b) Key structural forest connectors can be identified by combining landscape spatial pattern and network analyses. Forest Ecology and Management 262, 150 - 60.

Schumaker N. H. (1996) Using Landscape Indices to Predict Habitat Connectivity. Ecology 77, 1210-25. 
Soons M. B., Heil G. W., Nathan R. \& Katul G. G. (2004) Determinants of long-distance seed dispersal by wind in grasslands. Ecology 85, 3056-68.

Soons M. B., Messelink J. H., Jongejans E. \& Heil G. W. (2005) Habitat Fragmentation Reduces Grassland Connectivity for Both Short-Distance and Long-Distance WindDispersed Forbs. Journal of Ecology 93, 1214-25.

Theobald D. M., Crooks K. R. \& Norman J. B. (2011) Assessing effects of land use on landscape connectivity: Loss and fragmentation of western U.S. forests. Ecological Applications 21, 2445-58.

Tischendorf L. \& Fahrig L. (2000) On the Usage and Measurement of Landscape Connectivity. Oikos 90, 7-19.

Urban D. L., Minor E. S., Treml E. A. \& Schick R. S. (2009) Graph models of habitat mosaics. Ecology Letters 12, 260-73.

Vergara P., Hahn I., Zeballos H. \& Armesto J. (2010) The importance of forest patch networks for the conservation of the Thorn-tailed Rayaditos in central Chile. Ecological Research 25, 683-90.

Visconti P. \& Elkin C. (2009) Using connectivity metrics in conservation planning when does habitat quality matter? Diversity \& Distributions $15,602-12$.

Wilcox B. A. \& Murphy D. D. (1985) Conservation Strategy: The Effects of Fragmentation on Extinction. The American Naturalist 125, 879-87. 


\section{Tables}

Table 1: Percentage of the total habitat area and the number of patches that are in the biggest component at distance thresholds of $50 \mathrm{~m}, 100 \mathrm{~m}, 250 \mathrm{~m}, 500 \mathrm{~m}$ and $1000 \mathrm{~m}$.

\begin{tabular}{lll}
\hline Distance threshold & Proportion of patch area in & Proportion of number of patches in \\
(m) & main component (\%) & main component (\%) \\
\hline 50 & 93.6 & 27.6 \\
100 & 94.8 & 39.4 \\
250 & 96.0 & 72.2 \\
500 & 98.7 & 85.9 \\
1000 & 99.6 & 96.4 \\
\hline
\end{tabular}


Table 2: The level of connectivity in the grassland vegetation types of Mpumalanga as the percentage of the total patch area of the vegetation type that is in the largest component and the weighted importance of the patches in each vegetation type for overall connectivity based on a $50 \mathrm{~m}$ threshold distance. Vegetation types are ordered by weighted importance values.

\begin{tabular}{|c|c|c|c|c|}
\hline \multirow[t]{2}{*}{ Vegetation type } & $\begin{array}{l}\text { Percentage } \\
\text { natural habitat } \\
\text { remaining in the }\end{array}$ & \multicolumn{2}{|c|}{$\begin{array}{l}\text { Total patch area in largest } \\
\text { component (\%) }\end{array}$} & \multirow[t]{2}{*}{$\begin{array}{l}\text { Weighted } \\
\text { importance }\end{array}$} \\
\hline & $\begin{array}{l}\text { remaining in the } \\
\text { vegetation type } \\
\text { in Mpumalanga }\end{array}$ & $50 \mathrm{~m}$ & $500 \mathrm{~m}$ & \\
\hline Wakkerstroom Montane Grassland & 86.8 & 100.0 & 100.0 & 6.26 \\
\hline Eastern Temperate Freshwater & 95.4 & 91.8 & 99.9 & 4.80 \\
\hline \multicolumn{5}{|l|}{ Wetlands } \\
\hline Steenkampsberg Montane Grassland & 81.9 & 97.8 & 99.5 & 4.70 \\
\hline Lydenburg Thornveld & 85.2 & 99.9 & 100.0 & 3.75 \\
\hline Paulpietersburg Moist Grassland & 67.6 & 97.9 & 99.9 & 3.59 \\
\hline Amersfoort Highveld Clay Grassland & 67.2 & 99.8 & 100.0 & 3.46 \\
\hline Sekhukhune Montane Grassland & 76.9 & 99.7 & 100.0 & 3.11 \\
\hline Long Tom Pass Montane Grassland & 59.9 & 93.8 & 98.7 & 2.58 \\
\hline KaNgwane Montane Grassland & 57.0 & 91.0 & 99.5 & 2.40 \\
\hline Eastern Highveld Grassland & 54.0 & 95.7 & 99.9 & 2.22 \\
\hline Low Escarpment Moist Grassland & 97.4 & 100.0 & 100.0 & 2.07 \\
\hline Rand Highveld Grassland & 62.4 & 95.6 & 97.4 & 1.87 \\
\hline Tsakane Clay Grassland & 66.6 & 99.4 & 100.0 & 1.78 \\
\hline Soweto Highveld Grassland & 58.6 & 98.9 & 100.0 & 1.74 \\
\hline
\end{tabular}


Ithala Quartzite Sourveld

Andesite Mountain Bushveld

Frankfort Highveld Grassland

Northern Escarpment Dolomite

Grassland

Northern Escarpment Quartzite

Sourveld

Barberton Montane Grassland
76.6

82.2

66.4

50.6

47.4

64.5
6.3

87.4

0.14

1.69

1.44

1.42

1.22

48.2

77.1

0.31 
Figure captions

Figure 1: (a) Number of Components, and (b) Integral Index of Connectivity of the grassland habitat patches of Mpumalanga including and excluding abandoned croplands.

Figure 2: The extent of the largest component in the landscape and all other small components at a distance threshold of (a) $50 \mathrm{~m}$, (b) $100 \mathrm{~m}$, (c) $250 \mathrm{~m}$, (d) $500 \mathrm{~m}$ and (e) $1000 \mathrm{~m}$

Figure 3: Habitat patch importance for overall landscape connectivity as the percentage difference in the Integral Index of Connectivity (IIC) for the removal of each patch at a threshold distance of $50 \mathrm{~m}$.

Figure 4: The weighted importance of grassland vegetation types in Mpumalanga shown as the weighted average of the percentage difference in the Integral Index of Connectivity. 
Figure 1
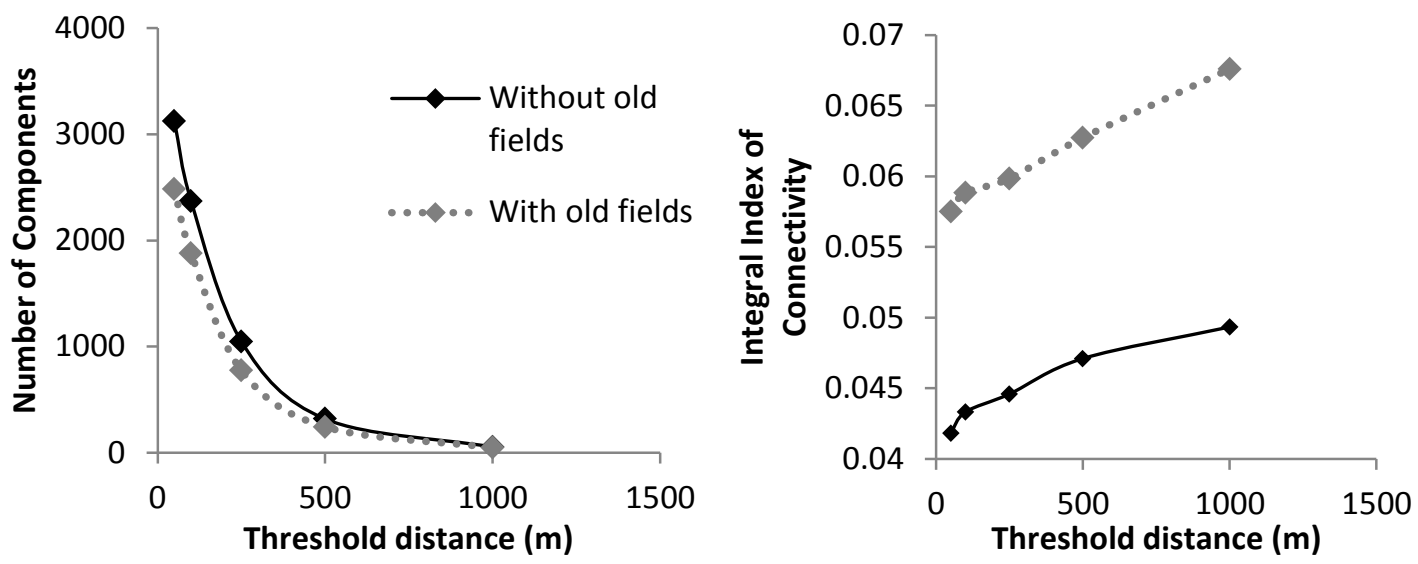

(a)

(b) 
Figure 2
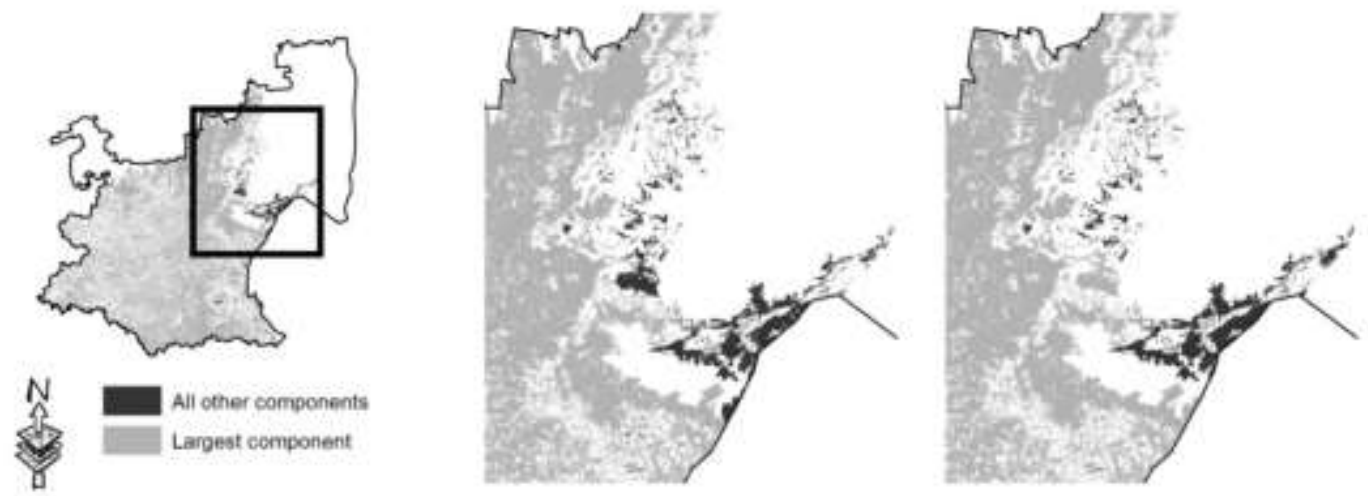

(a) $50 \mathrm{~m}$

(b) $100 \mathrm{~m}$
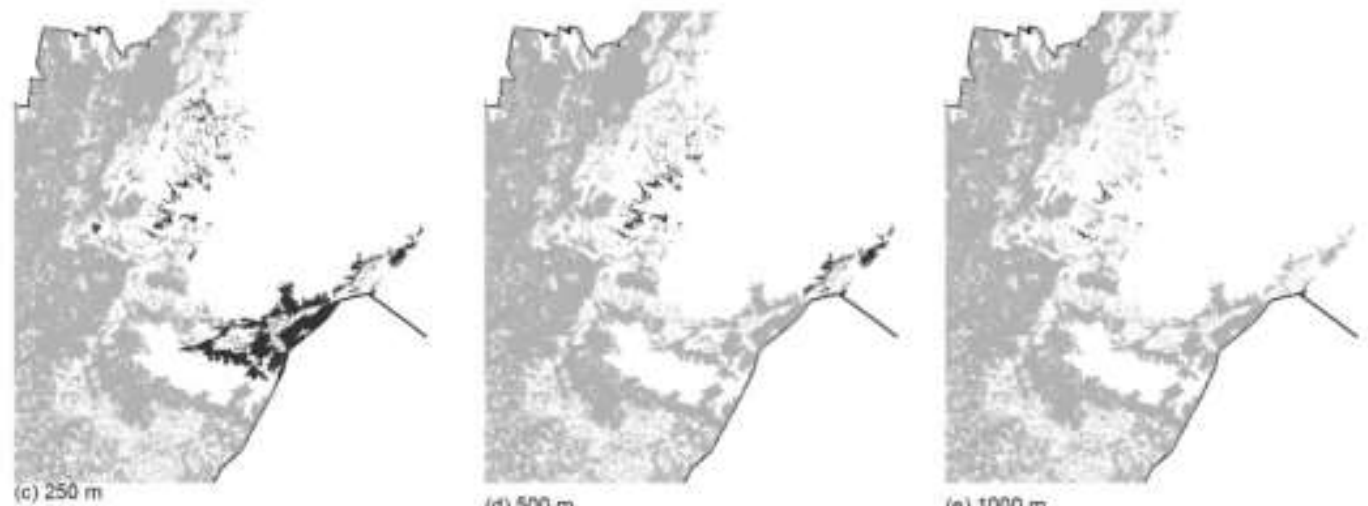

(a) $1000 \mathrm{~m}$ 
Figure 3

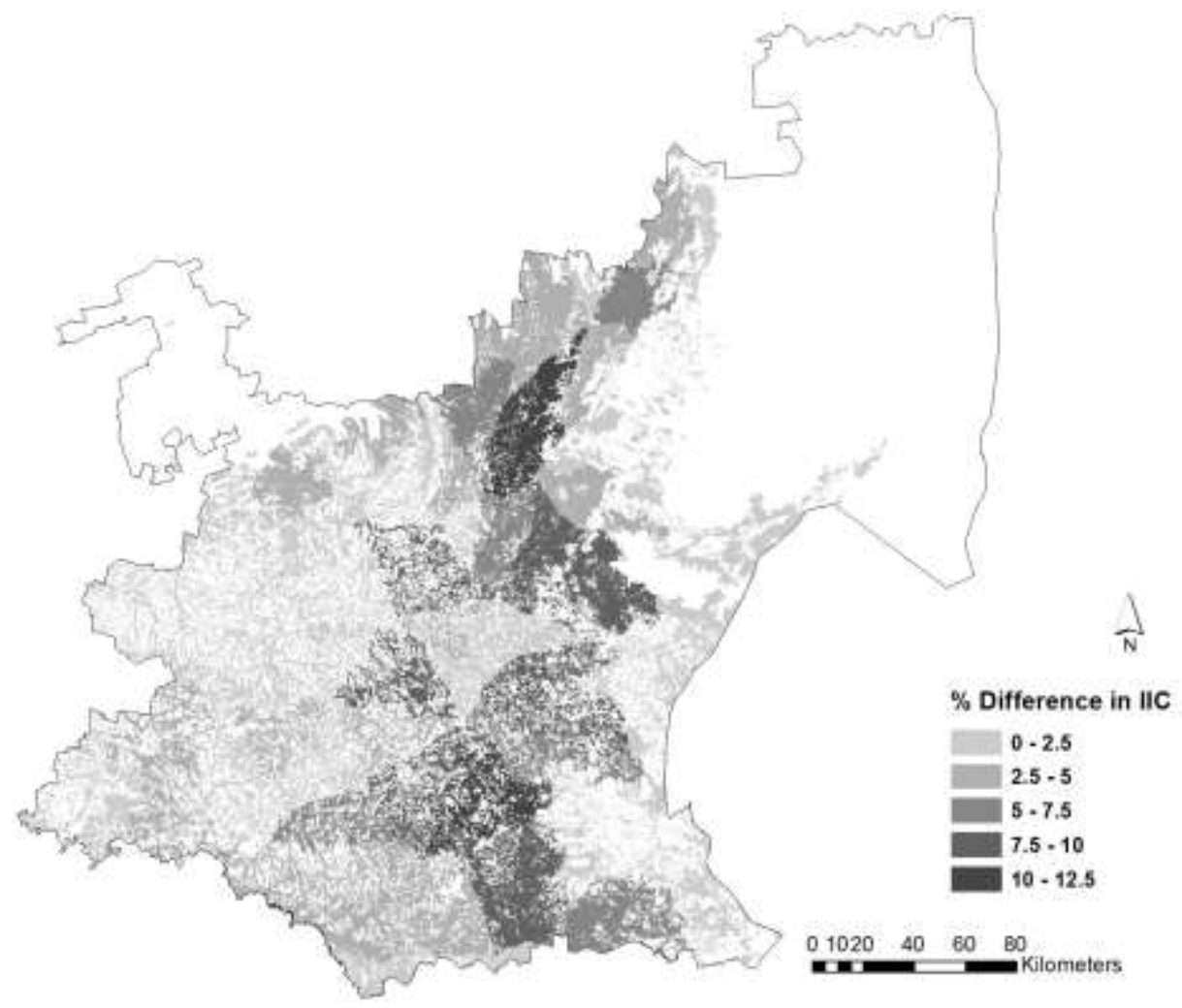


Figure 4

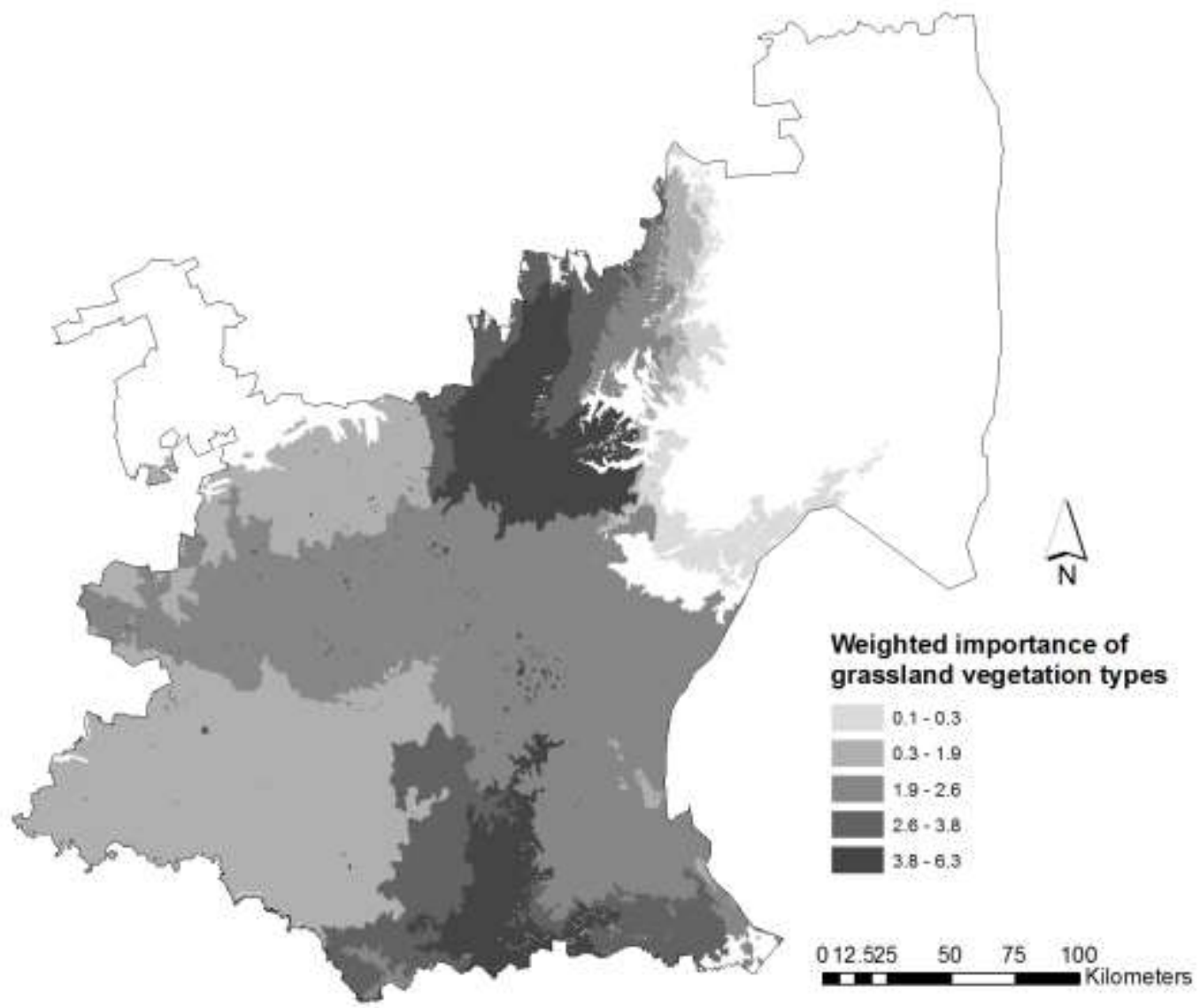

